\title{
Increasing Relationship Between Negative Emotionality and Conduct Problems During Childhood: A Cross-Sectional Behavioral Genetic Analysis
}

\author{
Yoon-Mi Hur, ${ }^{1}$ Sunyung Hwang, ${ }^{2}$ and Un-Sun Chung ${ }^{2}$ \\ ${ }^{1}$ Department of Education, Mokpo National University, Jeonnam, South Korea \\ ${ }^{2}$ Department of Psychiatry, Kyungpook National University Hospital, Daegu, South Korea
}

\begin{abstract}
Age difference in the etiology of the relationship between childhood negative emotionality (NE) and conduct problems (CP) has not been previously investigated. Mothers of 662 pairs of twins completed questions on the emotionality (NE) scale of the EAS temperament survey and the CP scale of the Strengths and Difficulties Questionnaires (SDQ) via a telephone interview. Twin data were analyzed separately in younger (ages 3 to 7 years; mostly pre-schoolers) and older children (ages 8 to 13 years; mostly elementary school children). The phenotypic correlation between NE and CP increased from 0.33 among younger twins to 0.43 among older twins. Bivariate model-fitting analysis was performed to determine age difference in the etiology of the relationship between NE and CP. Among younger twins, the correlation between NE and CP was entirely explained by additive genetic factors common to NE and CP. Among older children, however, a small but significant amount of unique environmental correlation emerged to account for about $47 \%$ of the phenotypic correlation between NE and CP. The remaining $53 \%$ of the phenotypic correlation was due to shared additive genetic factors. We speculate that environmental factors associated with school adjustment may exert influences on the relationship between NE and CP among elementary school children.
\end{abstract}

Keywords: negative emotionality, conduct problems, twins, genes, environment, school adjustment

NE is characterized by a predominance of negative affect, including distress and anger (Eysenck et al., 1985). The developmental propensity model proposes that NE interacts with adverse environmental conditions to influence the manifestation of CP (Lahey \& Waldman, 2003). In support of this theoretical proposition, significant associations between NE and CP have been reported (e.g., Eisenberg et al., 2005). Furthermore, recent twin studies have shown that common genetic and environmental sources are responsible for the association between NE and CP (Hink et al., 2013; Singh \& Waldman, 2010; Tackett et al., 2011; 2013; Taylor et al., 2013; Waldman et al., 2011). For example, using twins aged from 4 to 17 years drawn from the Georgia twin registry, Singh and Waldman (2010) investigated underlying genetic and environmental influences on the covariations among parent-reported NE and four externalizing symptoms (oppositional defiant disorder, conduct disorder, inattention, and hyperactivity/impulsivity). For conduct disorder, $45 \%$ of the non-additive genetic variance and $53 \%$ of the unique environmental variance overlapped with those for NE; the remaining 55\% of the non-additive and $47 \%$ of the unique environmental variances were those specific to conduct disorder. With a large population-based sample of twins (age: 6 to 18 years) born in Tennessee, Waldman et al. (2011) further demonstrated that $86 \%$ of the covariation between NE and a latent dimension of conduct disorder rated by parents and self could be explained by additive genetic factors.

Using the Tennessee twin sample, Tackett et al. (2011) extended the results of the Singh and Waldman study (2010)

RECEIVED 25 July 2015; ACCEPTED 31 August 2015. First published online 7 October 2015.

ADDRESS FOR CORRESPONDENCE: Department of Psychiatry, Kyungpook National University Hospital, Daegu, South Korea. 
by showing that genetic factors in NE played an important role in explaining the comorbidity of conduct disorder and major depressive disorder. The authors found that additive genetic factors in the comorbidity of conduct disorder and major depressive disorder were $19 \%$, which stemmed entirely from additive genetic factors in NE in males. However, the authors failed to replicate these results in female twins. Failure of replication in females may be due to a low prevalence rate of comorbid conditions in the study sample as the sample was a population-based one, which may have decreased the power to detect etiological links. Further studies are necessary to make a firm conclusion on gender difference (or equality) in the etiological link between NE and conduct disorder-major depressive disorder comorbidity.

Subsequently, three other twin studies further extended the Waldman et al. study (2011) to include externalizing factor (Taylor et al., 2013), internalizing and externalizing factors simultaneously (Hink et al., 2013), and the general factor of psychopathology (Tackett et al., 2013) in their models. In spite of the varying assessment methods and informants across studies, these studies consistently suggested that common additive genetic factors and unique environmental factors are substantive causes of the covariation between $\mathrm{NE}$ and conduct disorder.

To date, most twin studies of the NE-CP relationship examined children with a large range of age. As these studies typically controlled the main effect of age in their analyses using the regression method, little is known about whether and how causal influences on the phenotypic relationship between NE and $\mathrm{CP}$ change with age during development. It has been speculated that expression of genetic and environmental effects may vary during childhood, leading to different genes or environmental factors affecting the same phenotype at different ages (Plomin, 1986). Indeed, prior studies have shown that with increasing age during childhood, genetic factors generally increase in most temperamental dimensions and other behaviors (Goldsmith, 1983; Hur, 2014), whereas shared environmental factors become important in CP (Burt, 2009). Thus, the magnitude of genetic and environmental covariations between $\mathrm{NE}$ and $\mathrm{CP}$ can also change during development.

Children's transition from pre-school into elementary school is a critical event in their lives. During early school years, children must face social role transitions and academic challenges. Day-to-day experiences in new school environments can exacerbate or mitigate predisposed risks, resulting in some children able to function better and others worse (Belsky \& MacKinnon, 1994; Ladd \& Price, 1987). In the present study, using pre-school and elementary school twins, we investigated if the phenotypic relationship between NE and CP differed between the two age groups. Then, we sought to understand underlying causes of age differences in the phenotypic relationship between NE and $\mathrm{CP}$ using bivariate model-fitting analysis.

\section{Methods}

\section{Sample}

Subjects in the present study were 662 complete pairs of twins (age: 3 to 13 years) drawn from the South Korean Twin Registry (SKTR; Hur et al., 2013). We divided the total sample into two age groups: younger (3-7 years) and older ( $8-13$ years) twins. Younger twins were mostly preschoolers. The mean age of the younger group was 5.0 years with a standard deviation of 1.3 years. The older group comprised of elementary school children. The mean age of the older twins was 10.4 years with a standard deviation of 1.3 years. Fifty-six percent of the younger twins and $55 \%$ of the older twins were males. To maximize statistical power of the sample, we combined males and females prior to twin analyses, which resulted in 90 pairs of monozygotic (MZ) and 167 pairs of dizygotic (DZ) twins in the younger group and 183 pairs of $M Z$ and 222 pairs of $D Z$ twins in the older twin group. The greater number of $\mathrm{DZ}$ than $\mathrm{MZ}$ twins in the present sample reflected recent increases in DZ twin births in South Korea (Hur \& Kwon, 2005; Hur \& Song, 2009).

Zygosity was determined from mothers' responses to questions about physical similarity of the twins and frequency of confusion by others (Ooki et al., 1993). However, as the questionnaire method is less accurate than DNA analysis to determine twins' zygosity, we removed twins with ambiguous zygosity from data analyses.

\section{Measures}

Negative emotionality (NE). To measure NE, we used the emotionality scale of a Korean version (Cheon, 2002) of the EAS temperament survey (Buss \& Plomin, 1984). The EAS temperament survey was developed from the theory that supports genetic origin of temperament and includes three scales, emotionality, activity, and sociability, which measure major dimensions of children's temperament. Psychometric properties of the Korean version of the EAS temperament survey have been well established (Cheon, 2002). The emotionality scale includes five items that assess children's temperamental distress and the tendency to become upset easily and intensely. Mothers of the twins were asked to rate their twin children's behaviors on a five-point Likert scale ranging from not at all true (1) to certainly true (5) through a telephone interview.

Conduct problems (CP). In order to assess twins' $\mathrm{CP}$, 25 items of the Korean version of the SDQ (Ahn et al., 2003) were administered to mothers of twins via a telephone interview. Interviews were conducted for each twin separately. SDQ is one of the most commonly used instruments for screening psychopathology in children and adolescents worldwide. It includes 25 items to represent five scales (Emotional Problems, Peer Problems, Hyperactivity/Inattention Problems, CP, and Prosocial Behavior). On the basis of 48 studies using the SDQ scales, Stone 


\section{TABLE 1}

Sample Size, Mean and Standard Deviation, and Twin Correlations and Cross-Twin Cross-Trait Correlations and their 95\% Cl for Negative Emotionality (NE) and Conduct Problems (CP) for Monozygotic (MZ) and Dizygotic (DZ) Twins by Age Group

\begin{tabular}{|c|c|c|c|c|c|c|c|c|c|}
\hline \multirow[b]{2}{*}{ Measure } & \multirow{2}{*}{$\begin{array}{l}\text { Age } \\
\text { group }\end{array}$} & \multicolumn{4}{|c|}{$\mathrm{MZ}$} & \multicolumn{4}{|c|}{$\mathrm{DZ}$} \\
\hline & & $N$ & Mean & $S D$ & $r$ & $N$ & Mean & $S D$ & $r$ \\
\hline \multirow[t]{2}{*}{ NE } & Younger & 180 & 13.12 & 4.61 & $0.33[0.13-0.50]$ & 334 & 12.71 & 4.35 & $0.01[-0.14-0.16]$ \\
\hline & Older & 366 & 11.43 & 4.20 & $0.51[0.40-0.61]$ & 444 & 11.73 & 4.55 & $0.24[0.11-0.36]$ \\
\hline \multirow[t]{3}{*}{$\mathrm{CP}$} & Younger & 180 & 1.74 & 1.55 & $0.51[0.34-0.65]$ & 334 & 2.01 & 1.73 & $0.21[0.07-0.35]$ \\
\hline & Older & 366 & 1.57 & 1.59 & $0.36[0.23-0.48]$ & 444 & 1.55 & 1.56 & $0.37[0.25-0.48]$ \\
\hline & & \multicolumn{5}{|c|}{ Cross-twin cross-trait correlation } & \multicolumn{3}{|c|}{ Cross-twin cross-trait correlation } \\
\hline \multirow[t]{2}{*}{$\mathrm{NE}-\mathrm{CP}$} & Younger & 180 & & & $0.28[0.14-0.41]$ & 334 & & & $0.09[-0.02-0.19]$ \\
\hline & Older & 366 & & & $0.18[0.07-0.27]$ & 444 & & & $0.14[0.04-0.23]$ \\
\hline
\end{tabular}

Note: Younger $=3-7$ years; Older $=8-13$ years. $95 \% \mathrm{Cl}$ are in parenthesis.

et al. (2010) concluded that internal consistency, test-retest reliability, and validity of the scales are satisfactory across different age groups and sexes. Additionally, the scales of the SDQ have been shown to be valid in identifying psychopathology in the community as well as in the clinical samples (Goodman et al., 2000a; 2000b) and have shown strong correlations with the scales of the child behavior checklist (Achenbach \& Rescorla, 2001).

The five items of the CP scale are: Often loses temper; Generally well behaved, and obedient to adults; Often fights with other children or bullies them; Often lies or cheats; and steals from home, school or elsewhere. Mothers of twins were asked to rate their twin children's behaviors on a 3point Likert scale ranging from not true (0) to certainly true (2).

\section{Statistical Analysis}

A bivariate Cholesky decomposition model was fit to the data to fulfill the purposes of the present study. The bivariate Cholesky model enables us to investigate the extent to which common genetic and environmental influences contribute to the relationship between two traits. The full bivariate Cholesky model in the present study included additive genetic, shared environmental, and unique environmental influences on NE (a11, c11, and e11), the corresponding influences specific to CP (a22, c22, and e22), and the corresponding influences common to NE and CP (a21, c21, and e21). Measurement error is confounded with unique environmental variances. We did not include non-additive genetic factors in our model as our sample size was not sufficiently large to separate additive versus non-additive genetic factors. The additive genetic and shared environmental and unique environmental covariance matrices were standardized to compute the respective correlation matrices across $\mathrm{NE}$ and $\mathrm{CP}$. The additive genetic correlation provides a measure of the extent to which NE and CP are influenced by the same sets of additive genes. Similarly, shared environmental and unique environmental correlations respectively represent the degree of overlap in shared family environmental factors and unique environmental factors for NE and CP.
We used the maximum likelihood raw data option in Mx (Neale et al., 2003) that calculates twice the negative log-likelihood (-2LL) of the data. Model fit test statistics included Akaike's information criterion (AIC; Akaike, 1987) and the likelihood ratio test (LRT). For a baseline comparison, a saturate model was created for each age group. Means, variances, and covariances were allowed to vary across zygosity groups in the saturated model. Three steps were taken: First, -2LL of the saturated model was compared to that of the full bivariate model for each age group to find whether it is justifiable to move from the saturated to the full model. Second, model parameters in the full models were constrained to be equal across two age groups to test for the significance of age differences in genetic and environmental influences on the relationship between NE and CP. Finally, model parameters were removed from the full model sequentially and the changes in -2LL were examined to determine the best-fitting, most parsimonious model, to explain the relationship between NE and CP.

\section{Results}

\section{Descriptive Statistics}

Table 1 presents means and standard deviations for $\mathrm{NE}$ and $\mathrm{CP}$ for MZ and DZ twins by age group. Older twins had consistently lower means than did younger twins for $\mathrm{CP}$ and $\mathrm{NE}$ in $\mathrm{MZ}$ and $\mathrm{DZ}$ twins, suggesting that children tend to become lower in NE and CP with age. These mean differences between the two age groups were significant at $p<.01$ with an exception of the $\mathrm{CP}$ scale in MZ twins. The decline of $\mathrm{CP}$ with age was consistent with the literature (Bongers et al., 2003).

For CP, twins were not significantly different across zygosity groups in the mean levels or variances, indicating absence of zygosity effects; the first- and the second-born twins were not significantly different in the mean level or variance, suggesting no birth order effects either. For NE, however, first-born twins had significantly greater mean than did second-born twins in both $\mathrm{MZ}$ and $\mathrm{DZ}$ twins, albeit in older twins only; variances were different between $\mathrm{MZ}$ and DZ twins, again in older twins only. In the younger 


\begin{tabular}{|c|c|c|c|c|c|c|c|}
\hline \multirow[b]{2}{*}{ Model } & \multirow[b]{2}{*}{ Description } & \multicolumn{6}{|c|}{ Test statistics } \\
\hline & & $-2 \mathrm{LL}$ & $d f$ & AIC & $\Delta d f$ & $\Delta \chi^{2}$ & $p$ \\
\hline 1 & Full ACE & 2803.9 & 1017 & 769.1 & & & \\
\hline 2 & Drop a11, a21, a22 & 2812.4 & 1020 & 772.5 & 3 & 8.5 & .03 \\
\hline 3 & Drop c11, c21, c22 & 2803.9 & 1020 & 763.9 & 3 & 0.0 & .99 \\
\hline 4 & Drop c11, c21, c22, a21 & 2818.0 & 1021 & 776.0 & 4 & 14.1 & .01 \\
\hline 5 & Drop c11, c21, c22, e21 & 2809.3 & 1021 & 767.3 & 4 & 5.4 & .25 \\
\hline 6 & Drop c11, c21, c22, e21, a11 & 2899.4 & 1022 & 855.4 & 5 & 95.4 & .00 \\
\hline 7 & Drop c11, c21, c22, e21, a22 & 2809.7 & 1022 & 765.7 & 5 & 5.8 & .33 \\
\hline \multicolumn{8}{|c|}{$\begin{array}{l}\text { Note: The best-fitting model is indicated in bold type. }-2 \mathrm{LL}=-2 \text { Log Likelihood. } \mathrm{A}=\text { additive } \\
\text { genetic factor; } \mathrm{C}=\text { shared environmental factor; } \mathrm{E}=\text { unique environmental factor including } \\
\text { measurement error. a11, c11, and e11= additive genetic (a11), shared environmental (c11), } \\
\text { and unique environmental influences (e11) on NE; a22, c22, and e22 = additive genetic (a22), } \\
\text { shared environmental (c22), and unique environmental influences (e22) specific to } \mathrm{CP} ; \text {; } 21, \text {, } \\
\text { c21, \& e21; additive genetic (a21), shared environmental (c21), and unique environmental } \\
\text { influences (e21) common to NE and CP. }\end{array}$} \\
\hline
\end{tabular}

twin group, NE showed no significant mean or variance differences between the two zygosity groups or between the first- and the second-born twins.

Whereas the distribution of NE was approximately normal (skewness $=0.24$, kurtosis $=-0.63$ ), that of $\mathrm{CP}$ was significantly skewed and kurtotic (skewness $=1.23$, kurtosis $=1.99$ ). Therefore, logarithmic transformation was performed on the scores of the $\mathrm{CP}$ scale, which resulted in skewness of -0.02 and kurtosis of -0.99 .

\section{Twin Correlations and Cross-Twin Cross-Trait Twin Cor- relations}

For NE, MZ twin correlations were consistently greater than DZ twin correlations in both age groups, supporting the importance of genetic influences (see Table 1). For CP, however, the pattern of twin correlations was different between the two age groups: In the younger group, MZ twin correlation was significantly greater than DZ twin correlation $(r$ $=0.51$ for $\mathrm{MZ}$ and $r=0.21$ for $\mathrm{DZ}$ ). In the older group, however, $\mathrm{MZ}$ and $\mathrm{DZ}$ twin correlations were similar to each other ( $r=0.36$ for MZ and $r=0.37$ for DZ). These results suggested that although genetic influences were predominant in the variation of CP during the pre-school period, shared environmental influences emerged and became important in the elementary school period.

The phenotypic correlations between NE and CP were 0.33 [95\% CI: $0.25-0.40$ ] in younger twins and 0.43 [95\% CI: $0.38-0.48$ ] in older twins. These two correlations were significantly different at $p<.05$, indicating that the relationships between the two traits significantly increased with age. Cross-twin cross-trait correlations were consistently greater in $\mathrm{MZ}$ than in $\mathrm{DZ}$ twins in both age groups, which indicated that genetic factors may mediate the relationship between NE and CP throughout childhood. However, MZ cross-twin cross-trait correlations were much lower than the phenotypic correlations, especially in the older twin group, indicating the presence of unique environmental factors in the relationship between $\mathrm{NE}$ and $\mathrm{CP}$ in the EA twins.
Bivariate model-fitting analyses statistically tested for the initial impressions gained from twin and cross-twin cross trait correlations.

\section{Model-Fitting Analysis}

For both younger and older twins, the differences in chisquare between the ACE and the saturated model were not significant $\left(\Delta \chi^{2}{ }_{(17)}=22.0 ; p>.20\right.$ for younger twins; $\Delta \chi^{2}{ }_{(17)}=27.5 ; p>.05$ for older twins), suggesting that the ACE model was acceptable to explain the data for both age groups. We next constrained the model parameters to be equal across two age groups, which resulted in a significant decrease in model fit $\left(\Delta \chi^{2}{ }_{(9)}=21.65 ; p=.01\right)$. We thus fit the full bivariate ACE model to the data separately for each age group.

Younger group. Table 2 presents the results of bivariate model-fitting analyses for the full ACE model and its nested models for the younger twins. A series of the model comparison suggested that Model 7 was the best. In the best-fitting model for the younger group (Figure 1), additive genetic and unique environmental variance components were, respectively, 0.22 [95\% CI: $0.14-0.33$ ] and 0.78 [95\% CI: $0.67-0.86$ ] for NE, and 0.48 [95\% CI: $0.35-0.60$ ] and 0.52 [95\% CI: $0.40-0.65$ ] for CP. The additive genetic correlation between NE and CP in the best-fitting model was 1.00 [95\% CI: 0.90-1.00]. Shared and unique environmental correlations were not significant and constrained to zero. These results indicated that overlapping additive genetic factors were largely contributed to the phenotypic correlation of 0.33 between NE and CP $(0.33=\sqrt{ } .22 * \sqrt{ } .48)$ and that neither shared nor unique environmental factors contributed to the phenotypic correlation between NE and CP.

Older group. Table 3 presents the results of bivariate model-fitting analyses for the full ACE model and its nested models for the older group. In the best-fitting model (Model 6, Figure 2), additive genetic and unique environmental variance components were, respectively, 0.10 [95\% 
TABLE 3

Results of Bivariate Model-Fitting Analysis for Older Twins

\begin{tabular}{llllllrl}
\hline & & \multicolumn{7}{c}{ Test statistics } \\
\cline { 2 - 7 } Model & Description & $-2 \mathrm{LL}$ & $d f$ & AlC & $\Delta d f$ & $\Delta \chi^{2}$ & $p$ \\
\hline 1 & Full ACE & 4309.4 & 1609 & 1091.3 & & & \\
2 & Drop a11, a21, a22 & 4322.9 & 1612 & 1098.9 & 3 & 13.6 & .00 \\
3 & Drop c11, c21, c22 & 4317.6 & 1612 & 1093.6 & 3 & 8.2 & .04 \\
4 & Drop a22, a21 & 4311.8 & 1611 & 1089.8 & 2 & 2.5 & .29 \\
5 & Drop a11, a21 & 4322.9 & 1611 & 1100.9 & 2 & 13.6 & .00 \\
6 & Drop c11, c21 & $\mathbf{4 3 0 9 . 9}$ & 1611 & 1087.9 & 2 & 0.6 & .75 \\
7 & Drop c22, c21 & 4317.6 & 1611 & 1095.6 & 2 & 8.2 & .02 \\
8 & Drop c11, c21, a21 & 4331.8 & 1612 & 1107.8 & 3 & 22.4 & .00 \\
9 & Drop c11, c21, e21 & 4349.2 & 1612 & 1125.2 & 3 & 39.8 & .00 \\
\hline
\end{tabular}

Note: The best-fitting model is indicated in bold type. $-2 \mathrm{LL}=-2$ Log Likelihood. $\mathrm{A}=$ additive genetic factor; $C=$ shared environmental factor; $E$ = unique environmental factor including measurement error. a11, c11, and e11 = additive genetic (a11), shared environmental (c11), and unique environmental influences (e11) on $\mathrm{NE}$; a22, c22, and e22 = additive genetic (a22), shared environmental (c22), and unique environmental influences (e22) specific to $C P$; $a 21, c 21$, and e21 = additive genetic (a21), shared environmental (c21), and unique environmental influences (e21) common to NE and CP.

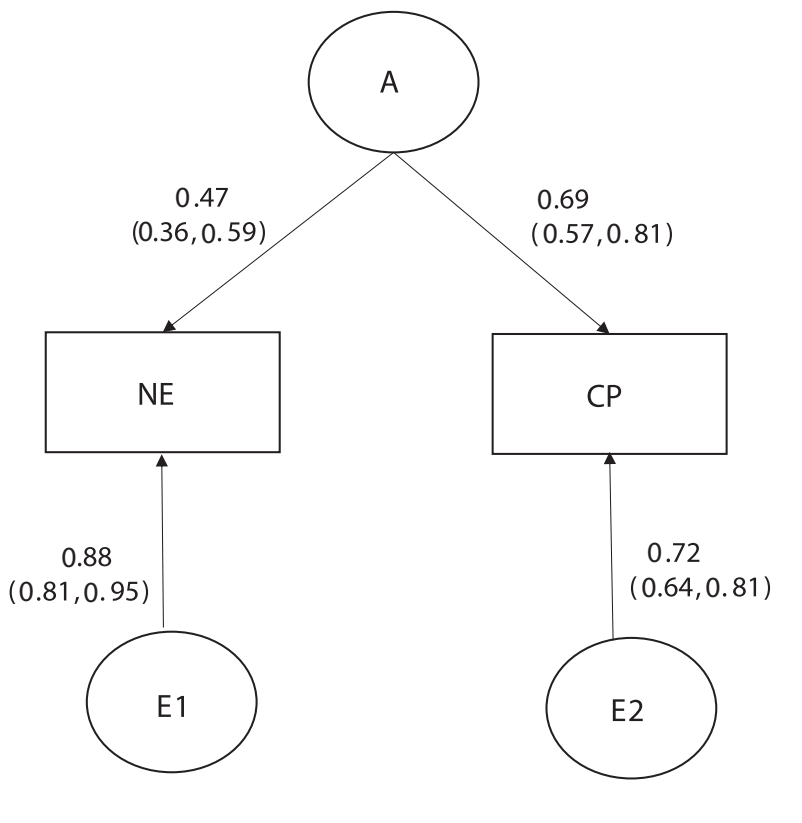

\section{FIGURE 1}

Standardized parameter estimates in the best-fitting bivariate model for the younger group.

Note: The estimates should be squared to obtain variance components. $95 \% \mathrm{Cls}$ are in parenthesis. NE = Negative Emotionality, $\mathrm{CP}=$ Conduct Problems. $\mathrm{A}=$ additive genetic influences, $\mathrm{E} 1=$ unique environmental influences and measurement error specific to Negative Emotionality, E2 = unique environmental influences and measurement error specific to Conduct Problems.

CI: 0.04-0.34] and 0.61 [95\% CI: 0.51-0.71] for CP, and $0.51[0.40-0.60]$ and 0.49 [0.40-0.60] for NE; shared environmental variance, 0.29 [0.09-0.36] was significant only for $\mathrm{CP}$; and additive genetic and unique environmental correlations between NE and CP were 1.0 [0.49-1.00] and 0.37 [0.26-0.47], respectively. A significant amount of shared environmental influences on $\mathrm{CP}$ was in agreement with other twin studies of CP based on early adolescents (Burt, 2009) and a prior study based on a subsample of the present study (Hur, 2015).

Taken together, the parameter estimates in the bestfitting model for older children suggested that 53\% ( $r=$ $0.23 ; 1.0 \times \sqrt{ } .10 \times \sqrt{ } .51)$ of the phenotypic correlation of 0.43 between CP and NE were attributable to correlated additive genetic factors, and the remainder, $47 \%(r=0.20$; $0.37 \times \sqrt{ } .61 \times \sqrt{ } .49$, to correlated unique environmental factors.

\section{Discussion}

There is growing evidence that NE is an important dispositional underpinning for the development of CP and other types of psychopathology. In line with previous studies, we found that common additive genetic factors were important sources to explain the relationship between NE and $\mathrm{CP}$ during childhood. Additionally, we found that the magnitude of the relationship between NE and CP increased from the pre-school to the elementary school period, and that while additive genetic factors played a major role in the relationship in both pre-schoolers and school-aged children, environmental factors emerged later among schoolaged children, and explained about half of the phenotypic relationship between NE and CP. Thus, our findings indicate that unique environmental experiences common to NE and CP significantly contributed to the increased phenotypic relationship between NE and CP among school-aged twins.

Environmental risk factors that have been found to contribute to the development of CP include maternal negativity (Caspi et al., 2004), and experience of peer rejection and selection of deviant peers (Laird et al., 2001). Unlike preschoolers, elementary school children experience the transition to the school and must cope with challenges such as 


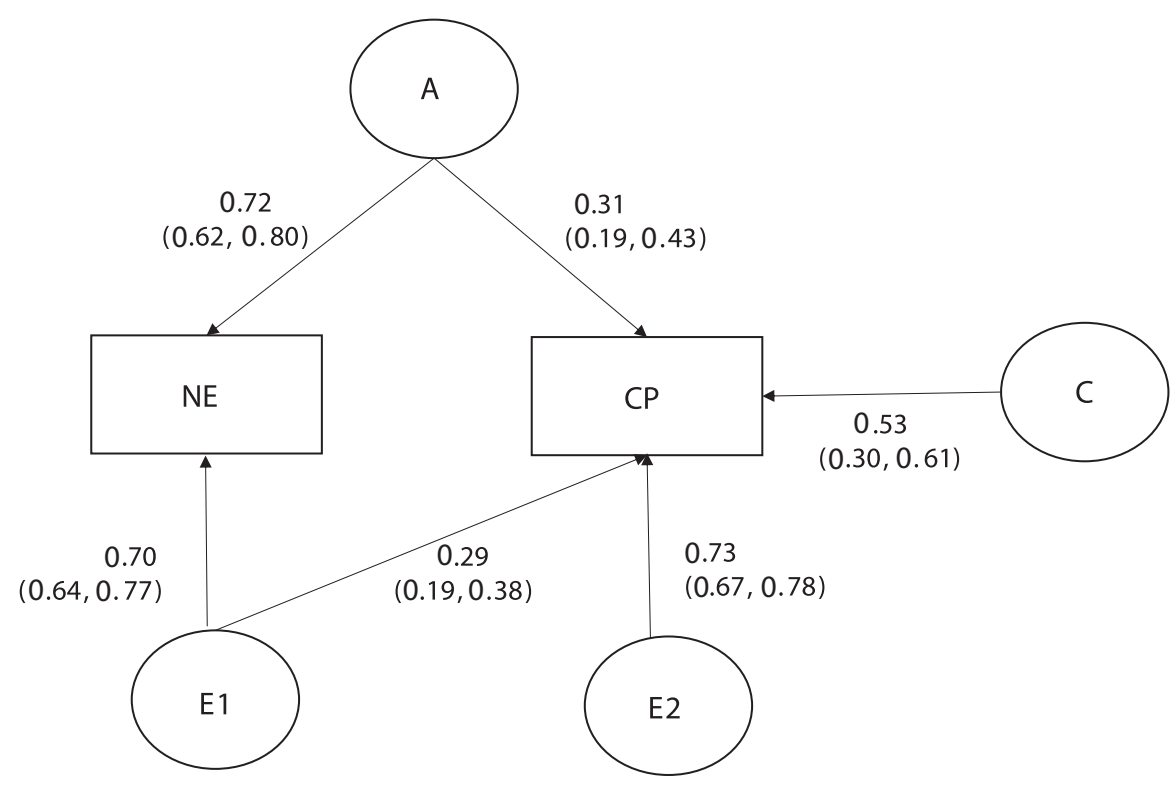

FIGURE 2

Standardized parameter estimates in the best-fitting bivariate model for the older group.

Note: The estimates should be squared to obtain variance components. $95 \% \mathrm{Cls}$ are in parenthesis. $\mathrm{NE}=\mathrm{Negative}$ Emotionality, $\mathrm{CP}=$ Conduct Problems. $\mathrm{A}=$ additive genetic influences, $\mathrm{C}=$ shared environmental influences, $\mathrm{E} 1=$ unique environmental influences and measurement error specific to Negative Emotionality, E2 = unique environmental influences and measurement error specific to Conduct Problems.

academic demands, learning classroom behavior management, and social relations with peers, teachers, and other adults in school and community (Ladd \& Price, 1987). These environmental factors may influence the relationship between NE and CP among school-aged children, leading to a higher correlation between the two traits among elementary school children as compared to pre-schoolers. For example, children high in NE may act aggressively when frustrated with environmental stressors associated with school adjustment. Aggressive behaviors in these children may cause them to be rejected by the main peer group and affiliate with deviant peers, and receive frequent punitive disciplines from teachers and other adults, which may further contribute to the development of NE and CP. Thus, the strength of the relationship between NE and CP may be increased with age, as the present study shows.

A study of South Korean elementary school twins showed that about $49 \%$ of lower graders (approximate ages 8-10 years) shared the classrooms/teachers, whereas only $19 \%$ of higher graders (approximately ages 11-13 years) did, and these rates did not vary across zygosity groups (Son et al., 2005). Thus, the results of the Son et al. study (2005) suggest that teacher/classroom experiences in two members of a twin pair in South Korea became more differentiated with increasing age, and the effects of teacher/classroom experience, if they existed, were more likely estimated as a unique environmental variance component in our model.

The unique environmental correlation between $\mathrm{NE}$ and $\mathrm{CP}$ found in the present study suggests that environmental intervention and prevention programs designed to reduce childhood CP may affect normative development of NE as well. Also, the emergence of unique environmental correlation among school-aged children suggests that the prevention programs for children at risk for $\mathrm{CP}$ may be most effective when implemented prior to the transition to the elementary school.

Molecular genetic studies have shown that genes involved in the monoamine oxidase A (MAOA) activity and serotonergic processes are associated with CP and NE (Brammer \& Lee, 2013; Fergusson et al., 2012). The additive genetic correlation of 1.0 found in both age groups indicates that genes for NE also increase $\mathrm{CP}$ in childhood. Thus, identification of genes involved in NE may facilitate the search for genes that confer risk for CD. However, it should be noted that the genetic component in twin designs may include the effects of gene-environment (GE) correlations and GE interactions as genetic effects can drive children to experience high-risk environment, which then moderates the expression of genes on behavioral development. Therefore, future twin studies should incorporate GE correlations and interactions explicitly in their models and investigate how genetic and environmental factors act and interact on the development of the relationship between NE and CP.

There are several limitations in the present study. First, although the present study detected age differences in the relationship between NE and CP phenotypically and etiologically, the sample sizes for each age group were relatively small for model-fitting analyses. Future analysis should 
employ a larger sample to confirm the conclusions drawn from the present study. Second, as both NE and CP of twin children were measured by maternal rating, the unique environmental correlation may include correlated measurement error. In future studies, the use of multiple measures and informants would be necessary to strengthen the results. Third, the results of the present study were based on cross-sectional twin data and therefore could not address whether NE precedes CP or vice versa. Future research should replicate the present results using longitudinal designs. A final limitation is that the present study was based on a South Korean twin sample. Although, the study well replicated previous findings of the significant relationship between NE and CP in Western samples, developmental differences in the etiology of the relationship between NE and CP have not been reported previously. Thus, the results await replications from other ethnic groups.

\section{Acknowledgment}

This work was supported by Biomedical Research Institute grant, Kyungpook National University Hospital.

\section{References}

Achenbach, T. M., \& Rescorla, L. A. (2001). Manual for the ASEBA School-age Forms and Profiles. Burlington, VT: University of Vermont, Research Center for Children, Youth, and Families.

Ahn, J.-S., Jun, S.-K., Han, J.-K., Noh, K.-S., \& Goodman, R. (2003). The development of a Korean version of the strengths and difficulties questionnaire. Journal of Korean Neuropsychiatric Association, 42, 141-147.

Akaike, H. (1987). Factor analysis and AIC. Psychometrika, 52, 317-332.

Belsky, J., \& MacKinnon, C. (1994).Transition to school: Developmental trajectories and school experiences. Early Education and Development, 5, 106-119.

Bongers, I. L., Koot, H. M., van der Ende, J., \& Verhulst, F. C. (2003). The normative development of child and adolescent problem behavior. Journal of Abnormal Psychology, 112, 179-192.

Brammer, W. A., \& Lee, S. S. (2013). Prosociality and negative emotionality mediate the association of serotonin transporter genotype with childhood ADHD and ODD. Journal of Clinical Child and Adolescent Psychology, 42, 809-819.

Burt, S. A. (2009). Rethinking environmental contributions to child and adolescent psychopathology: A meta-analysis of shared environmental influences. Psychological Bulletin, 135, 608-637.

Buss, A. H., \& Plomin, R. (1984). Temperament: Early Developing Personality Traits. Hillsdale, NJ: Erlbaum.

Caspi, A., Moffitt, T. E., Morgan, J., Rutter, M., Taylor, A., Arseneault, L., ... Polo-Tomas, M. (2004). Maternal expressed emotion predicts children's antisocial behavior problems: Using monozygotic-twin differences to identify environmental effects on behavioral development. Developmental Psychology, 40, 149-161.

Cheon, S. Y. (2002). The differential developmental pattern by child temperamental types and parental styles: A study on 'goodness of fit' in a developmental context (Unpublished masters thesis). Yonsei University, Korea.

Eisenberg, N., Sadvosky, A., Spinrad, T. L., Fabes, R. A., Losoya, S. H., Valiente, C., ... Shepard, S. A. (2005). The relations of problem behavior status to children's negative emotionality, effortful control, and impulsivity: Concurrent relations and prediction of change. Developmental Psychology, $41,193-211$.

Eysenck, H. J., Eysenck, S. B. G., \& Barrett, P. (1985). A revised version of the psychoticism scale. Personality and Individual Differences, 6, 21-29.

Fergusson, D. M., Boden, J. M., Horwood, L. J., Miller, A., \& Kennedy, M. A. (2012). Moderating role of the MAOA genotype in antisocial behaviour. British Journal of Psychiatry, 200, 116-123.

Goldsmith, H. H. (1983). Genetic influences on personality from infancy to adulthood. Child Development, 54, 331355.

Goodman, R., Ford, T., Simmons, H., Gatward, R., \& Meltzer, H. (2000a). Using the strengths and difficulties questionnaire (SDQ) to screen for child psychiatric disorders in a community sample. British Journal of Psychiatry, 177, 534539.

Goodman, R., Renfrew, D., \& Mullick, M. (2000b). Predicting type of psychiatric disorder from strengths and difficulties questionnaire (SDQ) scores in child mental health clinics in London and Dhaka. European Child and Adolescent Psychiatry, 9, 129-134.

Hink, L. K., Rhee, S. H., Corley, R. P., Cosgrove, V. E., Hewitt, J. K., Schulz-Heik, R. J., ... Waldman, I. D. (2013). Personality dimensions as common and broadbandspecific features for internalizing and externalizing disorders. Journal of Abnormal Child Psychology, 41, 939957.

Hur, Y.-M. (2014). Increasing phenotypic and genetic variations in hyperactivity/inattention problems from age 3 to 13 years: A cross-sectional twin study. Twin Research and Human Genetics, 17, 545-552.

Hur, Y.-M. (2015). Genetic and environmental etiology of the relationship between childhood hyperactivity/inattention and conduct problems in a South Korean twin sample. Twin Research and Human Genetics, 18, 290-297.

Hur, Y.-M., Jeong, H.-U., Chung, K. W., Shin, J. S., \& Song, T.-B. (2013). The South Korean twin registry: An update. Twin Research and Human Genetics, 16, 237-240.

Hur, Y.-M, \& Kwon, J. S. (2005). Changes in twinning rates in South Korea; 1981-2002. Twin Research and Human Genetics, 8, 76-79.

Hur, Y.-M. \& Song, T.-B. (2009). A recent rise in twin birth rates in South Korea and demographic characteristics of mothers of twins: 2003-2007. Twin Research and Human Genetics, 10, 373-378.

Ladd, G. W., \& Price, J. M. (1987). Predicting children's social and school adjustment following the transition from 
preschool to kindergarten. Child Development, 58, 11681189.

Lahey, B. B., \& Waldman, I. D. (2003). A developmental propensity model of the origins of conduct problems during childhood and adolescence. In B. B. Lahey, T. E. Moffitt \& A. Caspi (Eds.), Causes of conduct disorder and juvenile delinquency (pp. 76-117). New York: Guilford Press.

Laird, R. D., Jordan, K. Y, Dodge, K. A., Pettit, G. S., \& Bates, J. E. (2001). Peer rejection in childhood, involvement with antisocial peers in early adolescence, and the development of externalizing behavior problems. Development and Psychopathology, 13, 337-354.

Neale, M. C., Boker, S. M., Xie, G., \& Maes, H. H. (2003). Mx: Statistical Modeling (5th ed.). Richmond, VA: Virginia Commonwealth University, Department of Psychiatry.

Ooki, S., Yamada, K., \& Asaka, A. (1993). Zygosity diagnosis of twins by questionnaire for twins' mothers. Acta Geneticae Medicae et Gemellologiae, 42, 17-22.

Plomin, R. (1986). Multivariate analysis and developmental behavior genetics: Developmental change as well as continuity. Behavior Genetics, 16, 25-43.

Singh, A. L., \& Waldman, I. D. (2010). The etiology of associations between negative emotionality and childhood externalizing disorders. Journal of Abnormal Psychology, 119, 376-388.

Son, Y.-K, Hur, Y.-M, \& Jeong, H.-U. (2005). The classroom assignment for twins. The Korean Journal of Educational Administration, 23, 243-259.
Stone, L. L., Otten, R., Engels, C. M. E., Vermulst, Ad. A., \& Janssens, M. A. M. (2010). Psychometric properties of the Parent and teacher versions of the strengths and difficulties questionnaire for 4- to 12-Year-Olds: A review. Clinical Child and Family Psychology Review, 13, 254274.

Tackett, J. L., Lahey, B. B., Van Hulle, C., A., Waldman, I. D., Krueger, R. F., \& Rathouz, P. J. (2013). Common genetic influences on negative emotionality and a general psychopathology factor in childhood and adolescence. Journal of Abnormal Psychology, 122, 11421153.

Tackett, J. L., Waldman, I. D., Van Hulle, C. A., \& Lahey, B. B. (2011). Shared genetic influences on negative emotionality and major depression/conduct disorder comorbidity. Journal of the American Academy of Child and Adolescent Psychiatry, 50, 818-827.

Taylor, J., Allan, N., Mikolajewski, A. J., \& Hart, S. A. (2013). Common genetic and non-shared environmental factors contribute to the association between socioemotional dispositions and the externalizing factor in children. Journal of Child Psychology \& Psychiatry, 54, 6776.

Waldman, I. D., Tackett, J. L., Van Hulle, C. A., Applegate, B., Pardini, D., Frick, P. J., ... Lahey, B. B. (2011). Child and Adolescent Conduct disorder substantially shares genetic influences with three socioemotional dispositions. Journal of Abnormal Psychology, 120, 57-70. 